\title{
Tooth Crowding
}

National Cancer Institute

\section{Source}

National Cancer Institute. Tooth Crowding. NCI Thesaurus. Code C62542.

The condition when the summation of the mesio distal width of the teeth is larger than the arch perimeter. 